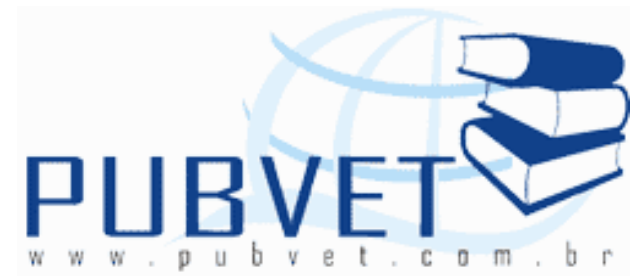

PUBVET, Publicações em Medicina Veterinária e Zootecnia.

\title{
Quimerismo sanguíneo em bovídeos: causas e implicações fisiológicas e genéticas*
}

Juliana Nobre Vieira ${ }^{1}$, Cláudia Salviano Teixeira ${ }^{2}$, Denise Aparecida Andrade de Oliveira ${ }^{2,3}$

${ }^{1}$ Doutoranda, Departamento de Zootecnia, Escola de Veterinária da UFMG, Belo Horizonte, MG, Brasil; Bolsista FAPEMIG - TCT n012.020/2009

${ }^{2}$ Escola de Veterinária da UFMG - Laboratório de Genética

${ }^{3}$ Professora Associada EV-UFMG - Orientadora

* Monografia apresentada à Disciplina "Tópicos Especiais em Melhoramento Animal: Quimerismo sanguíneo em bovídeos, causas e implicações fisiológicas e genéticas" ${ }^{1}$ Correspondência: nobrevieira.j@gmail.com

\section{Resumo}

A Síndrome do Freemartin é consequência da anastomose de vasos sanguíneos na placenta entre os gêmeos de sexos diferentes. O freemartinismo resulta na subfertilidade dos machos e da masculinização e infertilidade da fêmea. Representa a forma mais frequente de interesexualidade em animais. Desta forma, esta síndrome é fator limitante tanto para o sistema reprodutivo, quanto para o produtivo em ambos os sexos, pois causa prejuízos econômicos nas propriedades.

Palavras-chave: freemartinismo, intersexualidade 
VIEIRA, J.N., TEIXEIRA, C.S. e OLIVEIRA, D.A.A. Quimerismo sanguíneo em bovídeos: causas e implicações fisiológicas e genéticas. PUBVET, Londrina, V. 5, N. 3, Ed. 150, Art. 1010, 2011.

\title{
Blood quimerism in bovidae: causes and physiological and genetic implications
}

\begin{abstract}
Freemartin syndrome is consequence of blood anastomosis in the placent between co-twins of different sexes. The freemartin results in subfertility of males and masculinization of females. Represent the most frequent form of intersexuality in animals. Thus, this syndrome is a limiting factor for both reproductive system and for production in both sexes, because it causes economic losses in the properties.
\end{abstract}

Keywords: freemartinism, intersexuality

\section{Introdução}

A reprodução é uma manifestação fenotípica resultante do sucesso de uma multiplicidade de eventos a ela associados. Ao conjunto destas características indicadoras da performance de reprodução dá-se o nome genérico de eficiência reprodutiva. Do ponto de vista econômico, é a característica mais importante do sistema produtivo. Já do ponto de vista genético, é o aspecto mais restritivo para a adoção de programas de melhoramento, porque impõe limites às intensidades de seleção e, em consequência, reduz os ganhos genéticos.

O rebanho de bovídeos vem crescendo de maneira constante e significativa em todo o mundo, tanto no âmbito reprodutivo quanto produtivo. Para tanto, são utilizadas cada vez mais controle zootécnico nas propriedades.

Mesmo com estes cuidados, o rebanho ainda é bastante sensível a problemas de reprodução como a ausência de estro, presença dos dois conjuntos de cromossomos sexuais, esterilidade e deficiência nos ductos sexuais de fêmeas e em machos, degeneração testicular, sêmen com anormalidades, criptorquidismo e hipoplasia testicular, como ocorre em casos de freemartinismo. 
VIEIRA, J.N., TEIXEIRA, C.S. e OLIVEIRA, D.A.A. Quimerismo sanguíneo em bovídeos: causas e implicações fisiológicas e genéticas. PUBVET, Londrina, V. 5, N. 3, Ed. 150, Art. 1010, 2011.

Esta revisão tem como objetivo demonstrar que a Síndrome do Freemartin ou Quimerismo Sanguíneo é um fator limitante para a reprodução e aos sistemas de produção, mostrando suas causas e implicações fisiológicas e genéticas.

\section{Revisão Bibliográfica}

\section{- $\quad$ Síndrome do Freemartin}

A síndrome freemartin é conhecida desde tempos antigos, já descrita em caprinos, ovinos, suínos, equinos, cervídeos, camelídeos, bovinos e bubalinos. É consequência da anastomose de vasos sanguíneos na placenta entre gêmeos de sexos diferentes, sendo que o resultado é a masculinização do trato reprodutivo da fêmea em vários graus (Iannuzzi et al., 2005; Padula, 2005; Jainudeen \& Hafez, 2004). Geralmente ocorre durante a $2^{\mathrm{a}}$ e $3^{\mathrm{a}}$ semanas de vida embrionária, antes da diferenciação do sexo que ocorre aproximadamente aos 45 dias de vida do embrião (Iannuzzi et al., 2005). A diferenciação gonadal está quase completa no momento da formação dos vasos sanguíneos da placenta, por isso, o número de células germinais que migram do saco vitelino as gônadas no sangue pela anastomose vascular para o outro gêmeo é provavelmente baixo. Mas, em 1969, depois de vários experimentos, Ohno concluiu que algumas vezes, a fusão coriônica e a anastomose vascular entre zigotos ocorrem antes da completa migração das células germinativas primordiais, para as cristas gonadais, e algumas dessas células migratórias podem ser transportadas pelo sangue para o outro embrião. Assim, o quimerismo das células germinais é outra posibilidade (Ohno, 1969).

O freemartinismo resulta da modificação sexual da fêmea pela troca sanguínea in útero de um feto macho, portanto, representa a forma mais frequente de interesexualidade em animais (Padula, 2005; Jainudeen \& Hafez, 2004). Vale ressaltar que gêmeos em bovídeos são conectados no útero por um único cordão umbilical. Consequentemente, as substâncias testiculares fetais migram do feto do macho para a fêmea, via anastomose placentária. Uma destas substâncias é androgênica que age estimulando o desenvolvimento dos ductos femininos de Wolf, a outra é o polipeptídeo não androgênico, que atua inibindo 
VIEIRA, J.N., TEIXEIRA, C.S. e OLIVEIRA, D.A.A. Quimerismo sanguíneo em bovídeos: causas e implicações fisiológicas e genéticas. PUBVET, Londrina, V. 5, N. 3, Ed. 150, Art. 1010, 2011.

o desenvolvimento dos ductos de Müller. Além dessas ações hormonais, células germinais podem migrar do feto macho para as formações genitais da fêmea até então diferenciadas. Este processo inibitório inicia-se em torno do $45^{\circ}-50^{\circ}$ dia de gestação, enquanto que a masculinização e o surge por volta do $80^{\circ}$ dia. No feto fêmea, a deformação sexual que se caracteriza pela atrofia dos ovários que são intra-abdominais e raramente migram através do canal inguinal, desenvolvimento variável do tecido testicular, subdesenvolvimento do útero, da cérvix, da vagina e, frequentemente, hipertrofia das vesículas seminais e clitóris. Em geral, a aparência externa de um animal freemartin é de fêmea, mas há casos em que se assemelha a macho. Ao nascer, a fêmea freemartin exibe clitóris maior e vagina ocluída. Não há evidência de espermatogênese e a testosterona parece ser o principal esteróide produzido pela gônada do freemartin. Já o feto macho desenvolve-se normalmente e sua fertilidade pode não ser afetada (DiMeo et al., 2008; Iannuzzi et al., 2005; Padula, 2005; Jainudeen \& Hafez, 2004; Pereira, 2004).

Duas teorias foram propostas para explicar este distúrbio reprodutivo: a hormonal e a celular. A teoria hormonal diz que os hormônios do macho gêmeo que alcançam a fêmea através da anastomose vascular e entre as placentas provocam masculinização das gônadas femininas. Já a teoria celular é baseada na troca de células que originam o sangue e células germinativas entre os fetos. Como resultante desta troca recíproca entre os gêmeos dizigóticos, ocorrem idênticos tipos de antígenos eritrocitários em ambos os gêmeos e aparece um quimerismo sexual cromossômico, 60,XX/XY (bovino) e $48, X X / X Y$ ou 50,XX/XY (búfalo), devido aos tecidos hematopoéticos e possivelmente gonadais, nos leucócitos mononucleares sanguíneos (Jainudeen \& Hafez, 2004). Em consequência desta troca de células hematopoéticas, estas permanecerão ativas pelo resto da vida dos animais. Um freemartin é uma fêmea genética na concepção, porém torna-se uma quimera sexual cromossômica, portanto, estéril. Toda fêmea freemartin é estéril (Di Meo et al., 2008; Iannuzzi et al., 2005; Jainudeen \& Hafez, 2004). 
VIEIRA, J.N., TEIXEIRA, C.S. e OLIVEIRA, D.A.A. Quimerismo sanguíneo em bovídeos: causas e implicações fisiológicas e genéticas. PUBVET, Londrina, V. 5, N. 3, Ed. 150, Art. 1010, 2011.

É importante ressaltar que um quimera sanguíneo é totalmente diferente de um quimera celular, são independentes. Portanto, podem acontecer isoladamente ou não. O quimerismo celular ocorre no início da divisão celular, durante a metáfase. Já o quimerismo sanguíneo ou freemartinismo, o de interesse nesta revisão, ocorre entre a segunda e terceira semana de vida embrionária (Iannuzzi et al. 2005).

\section{- Estudos de casos de Freemartinismo}

Di Meo et al. (2008) avaliaram 30 búfalos de rio, 119 fêmeas com problemas reprodutivos e dois machos gêmeos e ambos sofreram exames clínicos e citogenéticos. Todas as fêmeas apresentaram conformação do corpo e genitália externa normais, porém tiveram sérios problemas nos ductos sexuais internos. Estas e os dois machos gêmeos (121 animais) apresentaram problemas reprodutivos, 25 animais apresentaram cromossomos sexuais anormais e todas as fêmeas eram estéreis devido a problemas nos ductos sexuais internos. As fêmeas foram descartadas.

Niku et al. (2007) estudaram bovinos que apresentaram quimerismo sanguíneo. Concluíram que por haver a mistura de sangue entre os fetos por volta dos 30-35 dias de gestação, a composição do sangue de ambos os gêmeos, macho e fêmea, seria a mesma. Aplicaram o método do Y-ISH, técnica extremamente específica e sensível para deteç̧ão do cromossomo $Y$, em fêmeas freemartin. O resultado foi positivo quando utilizado amostra de sangue e negativo quando usado qualquer outro tipo de tecido para extração de DNA, ou seja, presença e ausência do cromossomo $Y$, respectivamente. Portanto, o sistema hematopoético freemartin é fortemente quimérico já a partir de fases iniciais do desenvolvimento fetal, antes mesmo do início da anastomose vascular funcional.

Portanto, em casos de quimerismo sanguíneo em animais, somente as fêmeas apresentam dois perfis genéticos. Os diferentes perfis genéticos são detectados quando se extrai o DNA do sangue e do pelo do mesmo indivíduo, Figura 01-A e B. 
VIEIRA, J.N., TEIXEIRA, C.S. e OLIVEIRA, D.A.A. Quimerismo sanguíneo em bovídeos: causas e implicações fisiológicas e genéticas. PUBVET, Londrina, V. 5, N. 3, Ed. 150, Art. 1010, 2011.

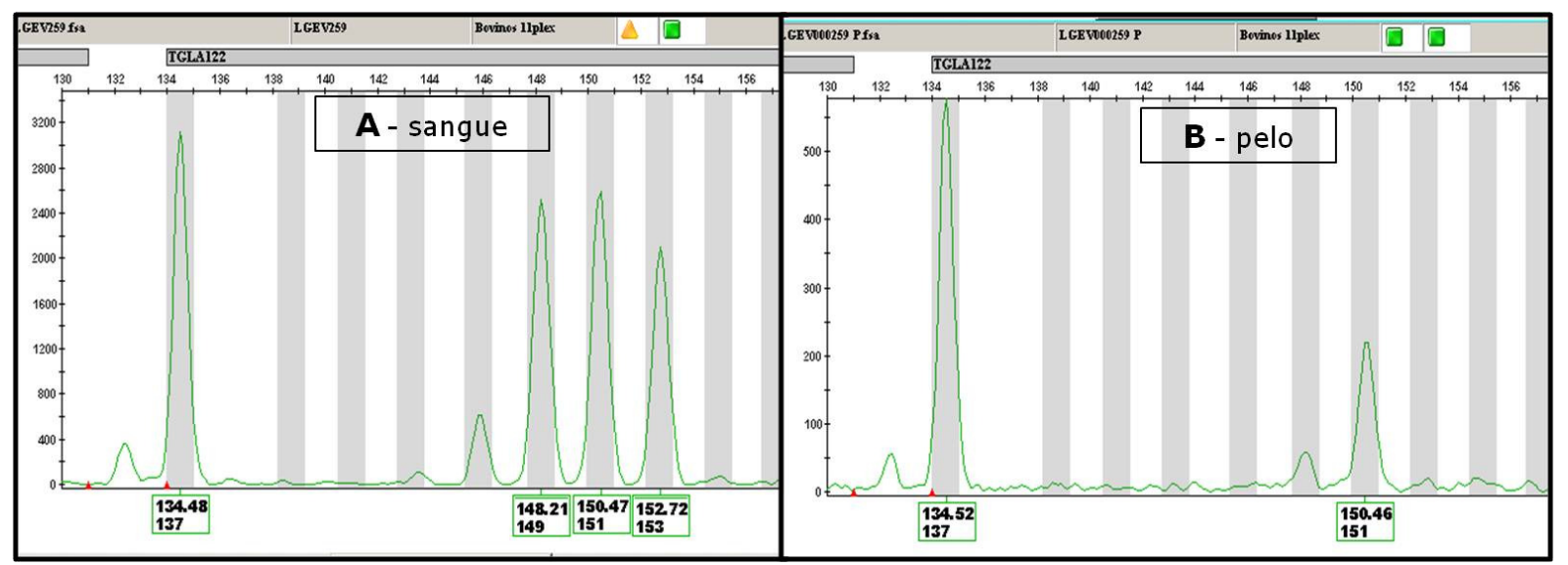

Figura 01: Quimerismo sanguíneo em bovinos, onde somente as fêmeas apresentam dois perfis genéticos. Os diferentes perfis genéticos são detectados quando se extrai o DNA do sangue (A) e do pelo (B) do mesmo indivíduo. FONTE: Laboratório de Genética da EV-UFMG.

Iannuzzi et al. (2005) estudaram 40 fêmeas de búfalos de rio fenotipicamente com problemas reprodutivos e dois machos gêmeos de fêmeas. Destes 42 animais, 10 eram freeemartin (oito fêmeas e dois machos), os dois machos apresentaram conformação de corpo e pênis normais, mas um deles desenvolveu significante redução de um dos testículos. Entre as oito fêmeas, seis apresentaram a formação do corpo, vagina e clitóris normais e as outras duas mostraram o trato genital de conformação de macho (pélvis fechada), apresentando fenótipo de macho. Outras observações clínicas foram: ovários pequenos ou não detectáveis, atrofia dos ductos de Müller e dos canais internos da vagina e vagina fechada com ausência dos canais internos. Também concluíram que todas as fêmeas freemartin eram estéreis, sendo descartadas, por serem estéreis. Este descarte leva a economia de tempo e dinheiro nas propriedades.

Padula (2005) observou que a fusão da circulação coriônica fetal de gêmeos macho e fêmea resulta em quimerismo nos descendentes. Existindo duas teorias em relação a touros: uma a razão do sexo da produção do descendente do macho e outra, a fertilidade que afeta machos na anormalidade seminal e, 
VIEIRA, J.N., TEIXEIRA, C.S. e OLIVEIRA, D.A.A. Quimerismo sanguíneo em bovídeos: causas e implicações fisiológicas e genéticas. PUBVET, Londrina, V. 5, N. 3, Ed. 150, Art. 1010, 2011.

citando outros autores que ao examinarem histologicamente, observaram áreas com pequenas e grandes degenerações testiculares, e casos de hipoplasia testicular.

Rejduch et al. (2000) encontraram dois touros nascidos de gestações gemelares que apresentaram espermatogônias que indicaram a presença de quimerismo $\mathrm{XY} / \mathrm{XX}$. A frequência de espermatogônias $\mathrm{XX}$ nos testículos dos touros avaliados não mostrou correlação com o número de células XX no sangue. O volume do ejaculado não foi afetado, enquanto a concentração e motilidade espermáticas foram menores quando comparados a touros com cariótipo normal. Com esta evidencia, é sugerido que as células XX nos testículos foram células germinativas primordiais da fêmea (Ohno, 1969). Esta condição em alguns casos está associada com mudanças na morfologia, motilidade e viabilidade dos espermatozóides e com defeitos no acrossoma ou, às vezes, com aspermia.

Kadokawa et al. (1995) relataram que no Japão, múltiplas transferências de embriões têm sido utilizadas para aumentar o número de filhos de vacas de alta produção, mas a taxa de sucesso se mantém baixa. No entanto, nos casos de partos de um só animal criado pela transferência de embriões, o freemartin pode existir. Em estudo realizado com 22 novilhas nascidas de gestações gemelares, 21 delas foram normais pela tipificação dos cromossomas e na PCR (não foram encontradas células masculinas e o DNA foram negativos). Somente uma delas foi classificada como normal pela tipificação dos cromossomas, mas foi classificada quimera heterossexual pela análise de PCR. Esta novilha apresentou trato reprodutivo interno e comportamento estral normais. Entretanto, na análise histológica foi observada no ovário esquerdo uma estrutura de $1,5 \mathrm{~mm}$ que se assemelha a vesícula seminal, enquanto que o resto do ovário apresentou folículos de Graff normais. Portanto, esta fêmea freemartin teve seu desenvolvimento sexual influenciado durante a gestação gemelar.

Khan \& Foley (1994) analisaram 217 casos de bovinos freemartin e diagnosticaram a síndrome através de achados clínicos (14 casos), pelo 
VIEIRA, J.N., TEIXEIRA, C.S. e OLIVEIRA, D.A.A. Quimerismo sanguíneo em bovídeos: causas e implicações fisiológicas e genéticas. PUBVET, Londrina, V. 5, N. 3, Ed. 150, Art. 1010, 2011.

cariótipo (141) e 62 pelo exame macroscópico do trato reprodutivo. Concluíram que a incidência do freemartin depende do número de partos gemelares de ambos os sexos e que esta condição é de suma importância econômica, pois resulta na esterilidade. Observaram diminuição do comprimento médio gonadal, gônadas localizando-se perto das glândulas mamárias, presença de epidídimo nas gônadas, ovário cístico, ausência de oocisto, masculinização do trato reprodutivo feminino. Análise cariotípica demonstrou variação do quimerismo do cromossomo sexual XY em fêmeas, resultando, assim, em quimerismo sanguíneo/freemartin.

Miyake et al. (1990) encontraram achados macroscópicos no útero subdesenvolvido de novilhas com quimerismo cromossômico $X X / X Y$, demonstrando a presença de vestígios de gônadas masculinas, assim como vesículas seminais na posição da cérvix, mas nenhuma célula germinal (ovócito, espermatozóide) foi encontrada.

Long (1979) propôs duas hipóteses do que pode acontecer quando ocorre o intercâmbio de células primordiais entre gêmeos. A primeira delas fala que as células germinais $X X$ nos testículos dos touros podem levar ao excesso de produção de espermatozóide $X$ e, por conseguinte à elevação do número de filhas nascidas. A segunda hipótese seria que as células germinais $X X$ no testículo do touro gêmeo não poderiam ser viáveis, e a sua degeneração levaria à reduzida fertilidade do touro.

Wijeratn et al. (1977) observaram nascimentos múltiplos (geralmente de gêmeos) com só um dos animais sendo freemartin. Isso tem sido descrito em grupos de novilhas subférteis com o trato reprodutivo interno normal, das quais, algumas foram quimeras $X X / X Y$, e algumas nasceram em partos simples. Suspeitando que essas freemartins foram o resultado da morte no útero do gêmeo macho.

A Tabela 01 mostra os fenótipos sexuais de gêmeos macho/fêmea, cariótipos e os possíveis sinais clínicos observados em Búfalos (Bubalus bubalis). 
VIEIRA, J.N., TEIXEIRA, C.S. e OLIVEIRA, D.A.A. Quimerismo sanguíneo em bovídeos: causas e implicações fisiológicas e genéticas. PUBVET, Londrina, V. 5, N. 3, Ed. 150, Art. 1010, 2011.

Tabela 01: Fenótipos sexuais de gêmeos macho/fêmea, cariótipos e os possíveis sinais clínicos observados em Búfalos (Bubalus bubalis)

\begin{tabular}{ccl}
\hline Sexo & Cariótipo & \multicolumn{1}{c}{ Sinais Clínicos } \\
\hline $\mathbf{F} \quad 2 n=50, X X / X Y$ & $\begin{array}{l}\text { Conformação normal do corpo, vulva e clitóris, atrofia dos ductos } \\
\text { sexuais internos e ductos de Müller, ovários pequenos ou ausentes, } \\
\text { ovário cístico, ausência de oocisto, vagina fechada, masculinização } \\
\text { do trato reprodutivo feminino; } \\
\text { Estéreis. }\end{array}$ \\
M $2 n=50, X X / X Y$ & $\begin{array}{l}\text { Conformações normais do corpo e genitália externa; } \\
\text { Hipoplasia testicular, criptorquidismo e anormalidade espermática. }\end{array}$ \\
\hline
\end{tabular}

\section{CONSIDERAÇÕES FINAIS}

Todos os autores citados obtiveram, praticamente, os mesmos resultados, a exemplo dos sinais clínicos em fêmeas freemartin: ovários pequenos ou não detectáveis, atrofia dos ductos de Müller e dos canais internos da vagina, vagina fechada com ausência dos canais internos, conformação do corpo normal ou com tamanho inferior, vulva, vagina ou clitóris normais ou anormais, pélvis fechada, masculinização do trato reprodutivo e fenótipo de macho. Concluíram, com unanimidade, que todas as fêmeas freemartin eram estéreis, portanto sendo descartadas, levando a economia de tempo e custo nas propriedades.

Com relação aos machos de parto gemelar com fêmeas, alguns autores mostraram que eles podem apresentar anormalidades no trato reprodutivo, como critorquidismo, hipoplasia testicular e deficiências espermatogênicas, podendo repassar estes distúrbios aos descendentes.

Ao analisarem búfalos cariotipicamente, todos concluíram que fêmeas machos freemartins apresentaram os dois conjuntos de cromossomos sexuais, 50XX e $50 X Y$.

Em quimerismo sanguíneo, somente as fêmeas apresentam dois perfis genéticos. Estes são detectados quando se extrai o DNA do sangue e do pelo do mesmo indivíduo.

Em sistema de produção de leite, os freemartins são pouco econômicos porque suas habilidades de concepção e subsequente lactação são prejudicadas, pois 
VIEIRA, J.N., TEIXEIRA, C.S. e OLIVEIRA, D.A.A. Quimerismo sanguíneo em bovídeos: causas e implicações fisiológicas e genéticas. PUBVET, Londrina, V. 5, N. 3, Ed. 150, Art. 1010, 2011.

não contribuem em nada com o ganho genético, uma vez que são estéreis. Mas a chance de criação para engorda existe, tendo validade a carcaça, pois se a fêmea freemartin for para a engorda, terá escore corporal/ganho de peso semelhante ao de animal normal (Padula, 2005).

Entretanto, não é viável a qualquer sistema produtivo o parto gemelar de sexos diferentes, pois é um fator limitante para a reprodução em ambos os sexos. Pois esta síndrome afeta tanto a fisiologia reprodutiva quanto a genética.

\section{Referência Bibliográfica}

DI MEO, G. P.; PECURATTI, A.; DI PALO, R. et al. Sex chromosome abnormalities and sterility in river buffalo. Cytogenet. and Genome Res. (DOI: 10.1159/000118751). V. 120, p:127$131,2008$.

IANNUZZI, L.; Di MEO, G. P.; PECURATTI, A. et al. Freemartinism in river buffalo: clinical and cytogenetic observations. Cytogenet. and Genome Res. (DOI: 10.1159/000081531). V. 108, p: 355-358, 2005.

JAINUDEEN, M.R; HAFEZ, E.S.E. Genética dos Distúrbios Reprodutivos. In: Reprodução Animal. 6.ed. São Paulo: Ed. Malone, p: 302-316, 2004.

KADOKAWA, H.; Minezawa M.; Yamamoto, Y. et al. Freemartinism among singleton bovine females born from multiple embryo transfer. Theriogenology. V. 44, p: 295-306, 1995.

KHAN, M.Z.; FOLEY, G.L. Retrospective Studies on the Measurements, Karyotyping and Pathology of Reproductive Organs of Bovine Freemartins. J. Comp. Path. V.110, p: 25-36, 1994.

LONG, S.E. The fertility of bulls born twin to freemartins: A review. T. Vet. Rec. V. 10, p: 211212, 1979.

MIYAKE, Y.; MURAKAMI, R.; KANEDA, Y. A single born infertile heifer with sex chromosome chimerism (XX/XY). J. Fac. Agr. Iwate. Univ. V. 19, p: 333-338, 1990.

NIKU, M.; PESSA-MORIKAWA, T.; TAPONEE, J. et al. Direct observation of hematopoietic progenitor chimerism in fetal freemartin cattle. BMC Veterinary Res. (DOI: 10.1186/17466148-3-29), (www.biomedcentral.com/1746-6148/3/29), 3:29, 2007.

OHNO, S. The problem of the bovine freemartin. J. Reprod. Fert., Suppl. V. 7, p: 53-61, 1969.

PADULA, A.M. The freemartin syndrome: na update. Animal Reprod. Scien. (DOI: 10.1016/j.anireprosci.2004.09.008), v.87, pp.93-109, 2005.

PEREIRA, J.C.C. Melhoramento genético aplicado à produção animal: aplicação da Biotecnologia Reprodutiva no Melhoramento Animal. 4.ed. Belo Horizonte: FEPMVZ Editora, p:427-439, 2004. 
VIEIRA, J.N., TEIXEIRA, C.S. e OLIVEIRA, D.A.A. Quimerismo sanguíneo em bovídeos: causas e implicações fisiológicas e genéticas. PUBVET, Londrina, V. 5, N. 3, Ed. 150, Art. 1010, 2011.

REJDUCHIA, B. et al. $60, X Y / 60, X X$ Chimerism in the germ cell line of mature bulls born in heterosexual twinning. Theriogen. 54:621-627, 2000.

WIJERATNE, W.V. et al. Heifer sterility associated with single-birth freemartinism. Vet. Rec. $100,333-336,1977$. 